\title{
Correction to: Gravity and Magnetic Processing and Inversion Over the Mahallat Geothermal System Using Open Source Resources in Python
}

\author{
Vahid E. Ardestani, ${ }^{1,2,3}$ (iD Dominique Fournier, ${ }^{3}$ and Douglas W. Oldenburg ${ }^{3}$
}

Correction to: Pure Appl. Geophys.

The original version of this paper was inadvertently published with an incorrect author name for the author Dominique Fournier.

The correct name is:

Dominique Fournier

The original article has been corrected. We apologise for any inconvenience caused to our readers.
Publisher's Note Springer Nature remains neutral with regard to jurisdictional claims in published maps and institutional affiliations.

(Published online July 5, 2021)

The original article can be found online at https://doi.org/10.1007/ s00024-021-02763-6.

1 Institute of Geophysics, University of Tehran, Tehran, Iran. E-mail: ebrahimz@ut.ac.ir

2 Center of Excellence in Survey Engineering and Disaster Management, Tehran, Iran.

3 University of British Columbia (UBC), Earth and Ocean Science Department (EOAS), Vancouver, Canada. E-mail: fourndo@gmail.com; doug@eoas.ubc.ca 